\title{
Web Series as Digital Brand
}

\author{
R D Santy ${ }^{1 *}$, D D Anwar ${ }^{2}$ \\ ${ }^{1}$ Departemen Manajemen, Universitas Komputer Indonesia, Indonesia \\ 2Departemen Ilmu Komunikasi, Universitas Komputer Indonesia, Indonesia \\ Email: *raeny.dwisanty@email.unikom.ac.id
}

\begin{abstract}
The purpose of this research is to explain the role of the Web Series in discussing and delivering messages to audiences about the "value" of the product, where the web series published on digital media such as Youtube that becomes the attractive promotional strategies for the consumers. This research used a qualitative method with a descriptive approach that explains the promotion strategy and brand engagement through the web series that became a new content marketing campaign. The results of this study are the increased proximity between customers and brand as well as the increased understanding brand which leads to brand awareness because attractive promotional strategies can attract the attention of consumers. The use of web series to build engagement with customers also has its own added value, where the web series can also be used as a product campaign such as Ax Indonesia, which released a Web Series Axelerate the series: Kostan AX/3 that is in conjunction with the launch of their new product, Pomade, and Facial Wash. This study concludes that the approach to consumers must be adjusted to the characteristics of consumers themselves so that messages can be conveyed more effectively and on target.
\end{abstract}

\section{Introduction}

The development of technology is increasingly fast, almost all elements in life are now related and use technology, as well as in the world of marketing and business. Where the use of technology in the marketing world, especially from the use of communication techniques and information technology would certainly be a strategy to bring a company or brand closer to its customers. According to Soegoto, the promotion strategy is the planning of organizational communication to consumers or their targets [1]. It is not only changing in communication channels but over time how brands communicate with customers also change that makes orientation is now more focused on customers [2] One way is by digital brand engagement through Web Series media. Web Series is an internet promotion practice in the form of episodes story development program, web series is not just the inclusion of logos, brands or other forms of sponsorship but more than that it is necessary to have coherence between the brand and the story that is presented because the wrong application will make a deviation of brand consistency [3] Web series are explained by the empowering of both users and advertisers to create and release their contents, a process facilitated by the democratization of the new technologies. Meanwhile, according to Hollebeek brand engagement is the level of 


\section{International Journal of Research and Applied Technology}

$1(2)(2021) 257-262$

Journal homepage: https://ojs.unikom.ac.id/index.php/injuratech

customer motivation regarding brand relationships and the context of customer thought that can be marked from several things ranging in terms of cognition, affection, and behavior related to interaction with the brand [4]

There have been several studies that discuss the use of digital media in brand engagement that currently the media digital like social media is not only used by consumers to know the products and services offered by brands but more than that, the emergence of social media has made connections between customers and customers with brands through certain interactions, especially regarding important information about the brand. [5] Also, the use of social media has also drastically influenced brand engagement, as stated by Jayasingh, et al. In his research namely Determinants of Customer Brand Engagement in Social Media Sites said that we were able to first identify an increase in a brand engagement where this relationship has a direct impact on buying interest [6].

The use of digital media at this time can be maximized to support the process and marketing activities. That brand engagement through digital media also increases customer involvement in adding value and potential that also facilitates the delivery of feedback and suggestions through available features such as likes and comments so that responses from consumers are also more quickly accepted, but this also become popular among customers who consider this as a measure of the extent of customer involvement with its brand [7]. Other research discussed Antecedents of consumer brand engagement and brand loyalty, stated that the expression, involvement and also brand participation became drivers of brand engagement where the aim was to test how the concept could be brand interaction with its customers so that intertwined [8] Brand engagement is the level of customer cognition, emotion, and behavior that represents the extent to which they can mobilize cognitive resources, emotions, and behavior in interaction with the brand. [9] From all those studies we get an overview of how social media such as Facebook plays a role in the process of brand engagement with customers, meanwhile the difference with the research that the author does is an author focused different media specifically YouTube web series as a tool to build the brand engagement.

The purpose of this study is to explain how the role of the Web Series in the approach and delivery of messages to the audience about the "value" of the product. Web series that are published on social media or digital like Youtube at this time become one of the attractive promotional strategies for the audience or consumers. This research used a qualitative method with a descriptive approach that explained the promotion strategy and brand approach through the web series which is now a new content marketing campaign.

\section{Method}

This study used descriptive methods that describe how web series becomes a brand strategy through content that was relatable to approach and engage with the customers, and also supported by literary studies of brand engagement through digital media.

\section{Results and Discussion}

Recently web series has become one of the contents that are often used by brand owners to build closeness with their customers. This is done as an effort to adjust the brand to the development of technology and consumer behavior [11,12]. Especially in today's digital era, technological developments have supported changes in new dimensions where consumers can be more involved with brands so that consumers' habits are shifted, they prefer something that can be used mobile. The use of social media such as Youtube is more increasing, even becoming 


\section{International Journal of Research and Applied Technology}

$1(2)(2021) 257-262$

Journal homepage: https://ojs.unikom.ac.id/index.php/injuratech

important in the world of marketing communications because it is very influential in influencing consumer habits. This trend makes customers use social media as a platform and source of information and builds the assumption that social media is one of the instruments of brand success [10].

In this study discuss the Web Series titled Axelerate the series: Kostan AX / 3, released by Brand Ax Indonesia. Axelerate the series tells about the lives of 3 boarding children who have diverse characteristics and backgrounds where each of them has different problems about their appearance.

In this web series how brands approach their customers can be seen from several things, including through media selection. The media adjustment with the content is also important because each media or channel has their respective advantages, such as the Web Series released through Youtube, which is certainly a form of the right approach considering that currently the public, especially the younger generation is more fond of digital media because of its easy access, it is also in line with the target market of Axe's products that target young people. Also, the use of digital media is considered appropriate to support the engagement with customers because of its interactive nature so that the brand will easily know the feedback delivered by the customer or in this case the audience of the web series. For example through likes, comments and the number of viewers from the Web Series released (See Figure 1).

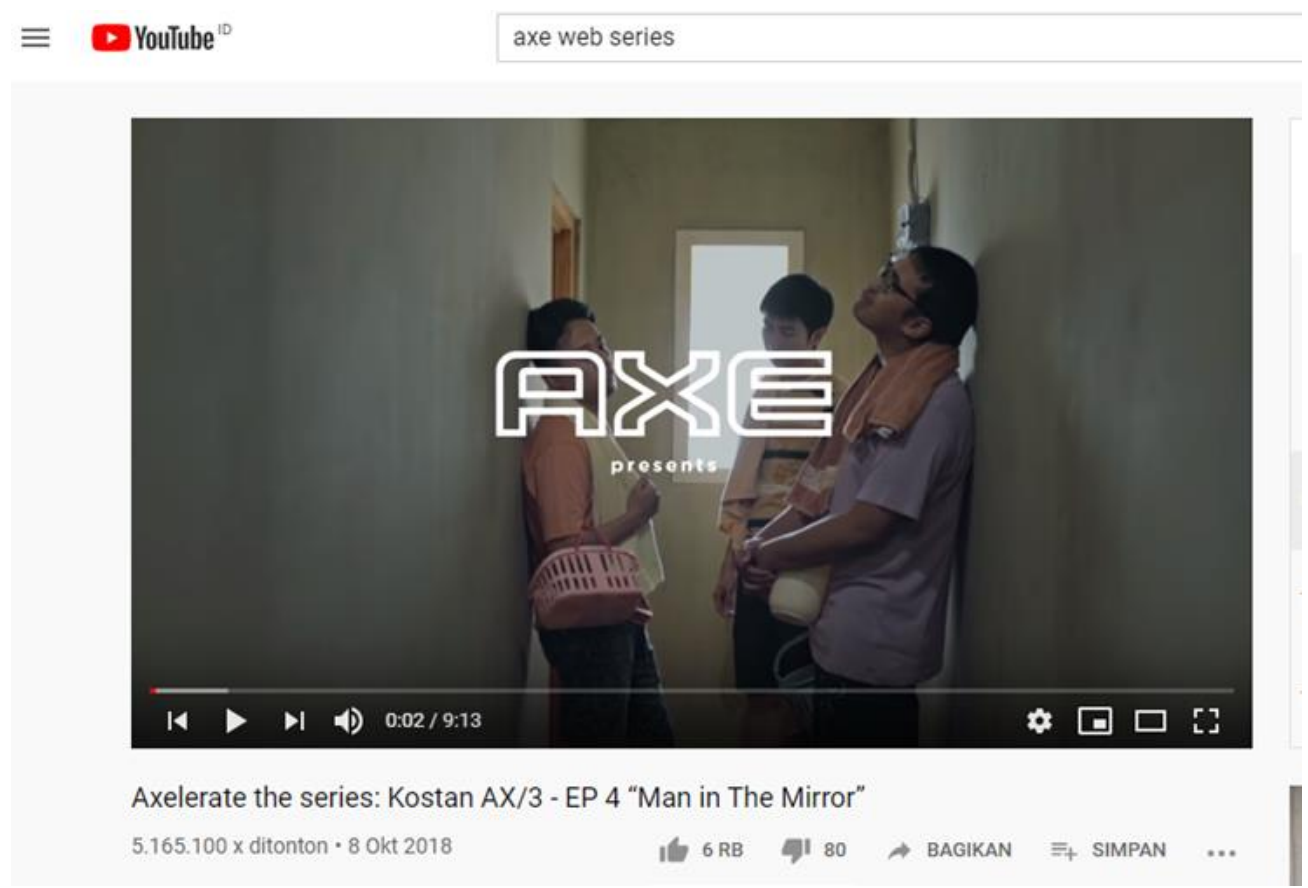

Figure 1. Viewers of Web Series Axelerate the series: Kostan AX/3 This figure was adapted from www.youtube.com on Oct 22, 2019.

Figure 1 shows Axelerate the series: Kostan AX / 3 episode 4 has been watched 5.1 million times and got 6 thousand likes. The number of viewers is relatively high when compared to other Web Series. Besides, the user of digital media such as Youtube also provides features to share so that customers who watch can share and recommend this web series to others.

Other than that, the approach can also be seen from how the brand efforts to maintain relationships with customers through content that is relevant to everyday life and 


\section{International Journal of Research and Applied Technology}

1(2)(2021) 257-262

Journal homepage: https://ojs.unikom.ac.id/index.php/injuratech

packaged attractively so it doesn't bring a commercial impression. This can be seen from how the appearance of Axe products has not been highlighted since the beginning of the episode so it doesn't disturb the storyline (See Figure 2).

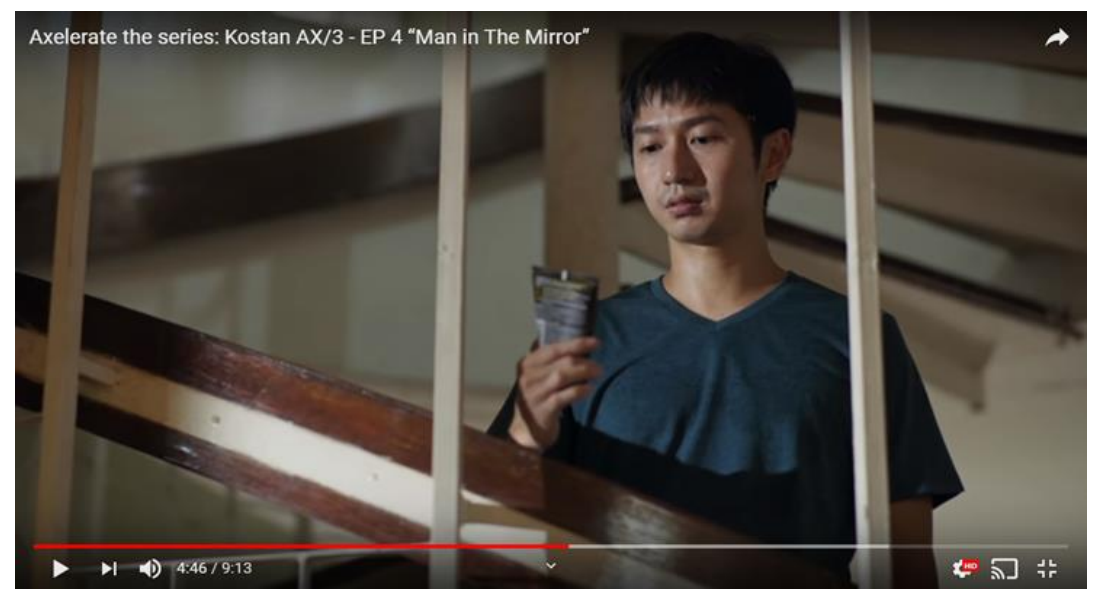

Figure 2. A scene from Axelerate the series: Kostan AX/3. This figure was adapted from www.yotube.com on Oct 22, 2019.

Figure 2 describing the scenes in a nicely packaged web series where Mas Jay, the owner of Kostan, asked Agit to wash his face so he will look fresher, in this scene the story was delivered interestingly so the message was not commercial.

The form of episodes of web series that are released periodically also becomes a strategy to maintain a close relationship with the customers because then the customer will be curious and wait for the next episode, for example, can be seen from the following picture

(See Figure 3).

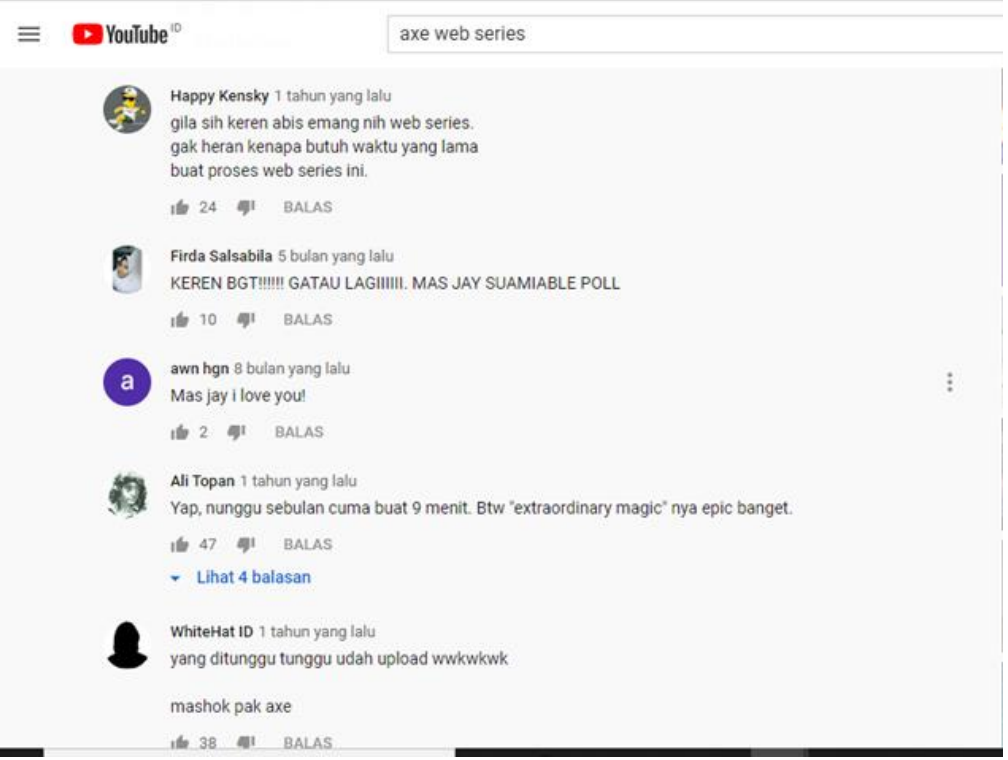

Figure 3. Comment of Axelerate the series: Kostan AX/3. This figure was adopted from www.youtube.com on Oct 22, 2019. 
In Figure 3 we can see how the audience comments about the Axelerate web series where most of them appreciate the storyline that is presented and enthusiast to wait for the next episode.

The use of digital media such as Youtube also certainly makes the brand more easily interact with consumers, the simple example is when the brand replied comment, this does seem trivial but it will make consumers feel more recognized so there is more closeness (See Figure 4).

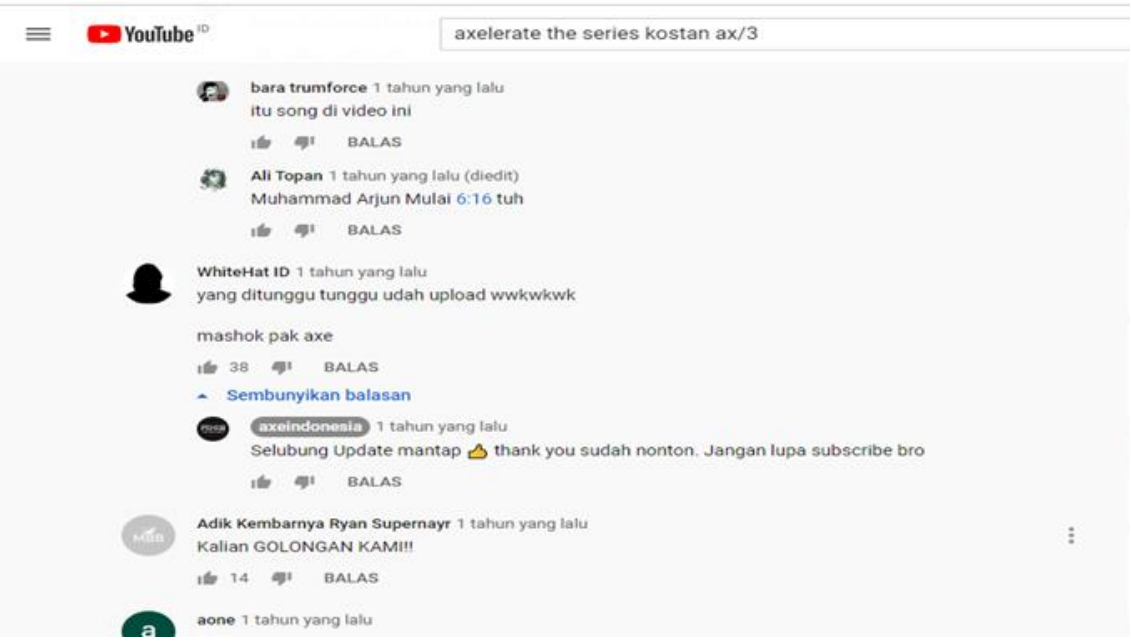

Figure 4. Comment replied by Axe . This figure was adopted from www.youtube.com/ on Oct 222019.

In Figure 4 we can see how the brand responds to comments from consumers about the web series content, the brand also takes a relaxed approach by adjusting the language and use informal language without seeming rigid.

Apart from the points above Brand Engagement tends to use an approach of cognition and affection where the cognition approach can be seen from how the brand informs the uses and benefits of its products so that indirectly by watching this Web Series customer become more familiar with the brand further or create brand awareness. Other than the cognitive approach, the Web Series also takes an effective approach where messages are delivered explicitly and prioritizes the story values of the Web Series itself.

The use of web series to build engagement with customers also has its own added value, where the web series can also be used as a product campaign such as Ax Indonesia, which released a Web Series Axelerate the series: Kostan AX/3 that is in conjunction with the launch of their new product, Pomade, and Facial Wash. Using the Web Series on Youtube as a way of promoting and campaigning will certainly help improve word of mouth about the product so that it helps with digital communication. 


\section{International Journal of Research and Applied Technology}

$1(2)(2021) 257-262$

Journal homepage: https://ojs.unikom.ac.id/index.php/injuratech

\section{Conclusion}

This study concludes that the approach to consumers must be adjusted to the characteristics of consumers themselves so that messages can be conveyed more effectively and on target. The use and maximization of digital media can also be used as a strategy for brands to build relationships with their customers, such as a web series that brings a new atmosphere so that the brand engagement with customers becomes easier and more intense.

\section{References}

[1] Soegoto, E. S. 2014. Entrepreneurship Becomes a Revised Edition Businessman. Elex Media Komputindo. 45 (3), (pp. 80- 98).

[2] Bowden, J. L. H., Conduit, J., Hollebeek, L. D., Luoma-aho, V., \& Solem, B. A. A. 2018. The role of social capital in shaping consumer engagement within online brand communities. The Handbook of Communication Engagement, pp. 491-504.

[3] Wan, P., Meng, X., \& Zhou, K. 2016. Effects of compound fertilizer on growth and soil nutrients in tung oil tree seedlings of Three Gorges Reservoir area. Southwest China Journal of Agricultural Sciences, 29(3), pp. 623-627.

[4] Hollebeek, L. D., Glynn, M. S., \& Brodie, R. J.2014. Consumer Brand Engagement in Social Media: Conceptualization, Scale Development and Validation. Journal of Interactive Marketing, 28(2), pp. 149-165.

[5] Kabadayi, S., \& Price, K. 2014. Consumer - brand engagement on Facebook: liking and commenting behaviors. Journal of Research in Interactive Marketing, 8(3), pp. 203-223.

[6] Jayasingh, S., \& Venkatesh, R. 2016. Determinants of Customer Brand Engagement in Social Media Sites: A Conceptual Framework. International Business Management, 10(15), pp. 2802-2807.

[7] Bowden, J. L. H., Conduit, J., Hollebeek, L. D., Luoma-aho, V., \& Solem, B. A. A. 2018. The role of social capital in shaping consumer engagement within online brand communities. The Handbook of Communication Engagement, pp. 491-504.

[8] Leckie, C., Nyadzayo, M. W., \& Johnson, L. W. 2016. Antecedents of consumer brand engagement and brand loyalty. Journal of Marketing Management, 32(5-6),pp. 558578

[9] D. Hollebeek, L., \& Chen, T. 2014. Exploring positively- versus negatively-valenced brand engagement: a conceptual model. Journal of Product \& Brand Management, 23(1), pp. 62-74

[10] Schivinski, B., \& Dabrowski, D. 2016. The effect of social media communication on consumer perceptions of brands. Journal of Marketing Communications, 22(2), pp. 189214.

[11] Soegoto, E. S., \& Palalungan, A. F. (2020, July). Web Based Online Inventory Information System. In IOP Conference Series: Materials Science and Engineering. 879(1), p. 012125.

[12] Soegoto, E. S., \& Pamungkas, R. S. (2018, August). Web-based information system services in a textile industry. In IOP Conference Series: Materials Science and Engineering 407(1), p. 012060. 